Comparative Philosophy Volume 10, No. 1 (2019): 213-217

Open Access / ISSN 2151-6014 / www.comparativephilosophy.org

https://doi.org/10.31979/2151-6014(2019).100115

CONSTRUCTIVE-ENGAGEMENT DIALOGUE (3.1)

\title{
REVIEW OF ATTENTION, NOT SELF BY JONARDON GANERI
}

\author{
CARLOS MONTEMAYOR \& ABROL FAIRWEATHER
}

\section{OVERVIEW}

Jonardon Ganeri's book is a signal contribution to philosophy. His fluency in philosophy of mind, epistemology, cognitive science, and classic Indian philosophy, among other traditions, has been previously highlighted (e.g., Arnold 2008; Brooks 2013; Westerhoff 2013). His recent book Attention, Not Self is a major achievement that synthesizes Ganeri's knowledge of philosophy and its history, in a truly intercultural way. Our focus will be on the modular and normative aspects of Ganeri's account of attention, highlighting possible areas of development and additions that would help complete the ambitious project of Attention, Not Self. The main topics we discuss are the relation between consciousness and attention, the importance of agency for normative evaluations, and the type of virtue theory that could best accommodate Ganeri's proposals, given the cognitive architecture he proposes.

A brief survey of the book suffices to appreciate the scope and ambition of Attention, Not Self. Ganeri defends a view of the mind in which attention, rather than the self, takes pride of place. Part I, on the priority of attention, surveys and analyzes classical sources in Indian philosophy (especially the work of Buddhaghosa) and compares them with many of the leading contemporary theories in philosophy. Ganeri argues that findings in cognitive science confirm classical Indian views of the mind. One of the main claims of this section is that the "agent-causal" self should play no role in a theory of mind. It remains to be seen if there are costs incurred when accounting for normative evaluation - an issue we explore below. Part II provides an attentional account of knowledge, focused on perceptual attention. We analyze how this attentional account of knowledge addresses issues involving epistemic normativity. Part III, "the calling of attention", further explores the psychology of visual attention, emphasizing the modular architecture of the mind that dispenses with

MONTEMAYOR, CARLOS: Associate Professor of Philosophy, San Francisco State University, California, USA. Email: cmontema@sfsu.edu

FAIRWEATHER, ABROL: Lecturer in Philosophy, San Francisco State University, California, USA. Email: abrol@sfsu.edu 
the agent-causal self. Part IV, "attention expanded", introduces several types of attention, underscoring narrative attention for episodic memory and empathetic attention. The concluding part $\mathrm{V}$, addresses issues about personal identity. Our focus here is on Ganeri's account of normative issues in epistemology.

Ganeri defends a functionalist account of attention, partly based on Anne Treisman's notion of a "window of consciousness," namely the thesis that attention does not work as a spotlight but rather as an aperture "whose shape, size, and tilt can be adjusted" (12). This adjustment depends fundamentally on the selective nature of attention, which works by excluding distractors and enhancing attended features, facilitating the solution of the binding problem - the binding of features that are reliably tracked and integrated into percepts, and which cannot be illusory bindings (114-116). These reliable functions of attention provide the basis for an epistemic psychology that Ganeri develops in Part II.

Two issues stand out from Ganeri's approach to core issues in philosophy of mind: the modularity of mind and the dependence of consciousness on attention. Ganeri proposes that a functional account of attention can explain the emergence of consciousness. For instance, in describing Buddhaghosa's second account of consciousness, concerning "the causal conditions under which consciousness arises," Ganeri explains: "consciousness arises at the end of a series of cognitive activities [...] each member a condition for the next" (42-43). Ganeri then provides a graphical depiction that illustrates how this view of consciousness is not only dependent on the functions of attention, but how it also implies a modular view of the mind (consistent with the no-self approach). A key question about this commitment to modularity is whether a modular view of the mind can provide enough agential involvement in order to justify value judgments. We examine this issue in detail below.

Regarding the dependence of consciousness on attention, it may be problematic for Ganeri's account to fully explain how consciousness emerges from the activities and functions of attention, particularly in the light of traditional objections to functional accounts of phenomenal consciousness (Nagel 1974; Block 1995; Chalmers 1996). In addition, because of the dependence of consciousness on attention, Ganeri is endorsing what is called a "single dissociation view" that states that consciousness cannot occur in the absence of attention. This view excludes influential contemporary views of phenomenal consciousness that propose that consciousness can occur in the absence of attention or that it is somehow "primitive" and independent from attention (see Montemayor and Haldajian 2015, chapter 3 for discussion). The central question for Ganeri's account is, how to address the traditional objections to functionalism about phenomenal consciousness given his noself, emergentist, and single dissociation commitments?

In epistemology, Ganeri may have considerable contributions to make to the psychology of knowledge, especially to reliabilist theories of knowledge. Attention, Not Self could be a welcome correction to the psychology of knowledge if Ganeri's account of attention has sufficient explanatory power to replace the psychology of propositional attitudes in epistemic theorizing. One challenge Ganeri faces is accounting for the full normativity of knowledge with an epistemic psychology that 
makes no appeal to agents. We have argued that knowledge can be understood as the virtuous sensitivity and insensitivity of attention (Fairweather and Montemayor 2017), from a virtue reliabilist perspective. However, these are manifestations of agency on our account (epistemic achievements must be manifestations of agency on any virtue theoretic account), so it is not clear that Ganeri's attention based epistemic psychology would support an adequate account of epistemic normativity.

\section{EPISTEMIC NORMATIVITY AND EPISTEMIC PSYCHOLOGY}

The agent-causal hypothesis Ganeri argues against has been a central plank in virtue theoretic accounts of epistemic normativity and non-lucky epistemic success (to satisfy Gettier worries). Virtue epistemology is considered an 'agent based' perspective in epistemology because of the widely shared view that a true belief must manifest the cognitive abilities of the agent to count as knowledge. Leading figures including John Greco (2010), Duncan Pritchard (2012), Ernest Sosa (2015) and Linda Zagzebski (1996) appeal to the normative properties of epistemic agents to account for anti-luck conditions on knowledge and the distinctive value knowledge has over a merely true belief. While there are important differences separating them, each appeals to epistemic agency, or success that is 'due to' the abilities of the agent, to capture essential desiderata in the theory of knowledge. Virtue epistemology thus appears to rely on the very thesis Ganeri denies throughout Attention, Not self.

What are the possibilities here? On the one hand, Ganeri appears to directly challenge the fundamental commitment of the agent based theorizing that has been a significant force over the last thirty years in epistemology. This suggests that the attentional turn defended by Ganeri and the agential turn in epistemology are moving in incompatible directions. On the other hand, current theorizing about epistemic agency in contemporary analytic epistemology might benefit handsomely by heeding suggestions and modifications from the psychology of attention, in which case the attentional turn Ganeri defends is not only compatible with the agential turn in epistemology, but may be a powerful ally going forward. Just as G. E. M. Anscombe famously called for improvements in moral psychology to guide normative theorizing in ethics, Ganeri may have substantial improvements to epistemic psychology for guiding normative theorizing in epistemology.

Ganeri assumes a broadly reliabilist notion of justification, or at least one that is compatible with externalism (130-133). Process reliabilism has long been criticized for its dependence on an impoverished epistemic psychology. Cases of "strange and fleeting processes", driving through barn-facade country and Mr. Truetemp show that epistemic success must occur because of (or in virtue of) the abilities of the epistemic agent to count as knowledge, not merely because of a process that happens to be reliable (see Greco 2010 for discussion of the "because of" relation). Virtue reliabilists like Sosa (2015) and Greco (2010) argue that we must replace the psychology of mere cognitive processes with a psychology of abilities and competences to escape the well-established problems facing process reliabilism. Greco calls the improved view "agent reliabilism" (2010). However, an improved 
epistemic psychology of abilities and competencies brings with it the presumption of a causally efficacious epistemic agent who is, somehow, in control of the cognitive process. This is where Ganeri would appear to depart from virtue reliabilist theories of knowledge, although he defends some form of reliabilism, as noted above.

Does Ganeri have an alternative way to procure the theoretical advantages claimed by agent based epistemology, or does he deny the value of the claimed advantages to begin with because they rest on a faulty epistemic psychology? If Ganeri's modular psychology of attention can support a form of reliabilism that delivers the needed improvements to process reliabilism, he would have an interesting competitor to some leading contemporary accounts of knowledge. This modular account must explain how in spite of the lack of a causally effective introspective agent, there is still a minimal type of epistemic agent who controls cognitive processing through her virtuous abilities and competencies.

We believe that Ganeri's proposal can be complemented with the virtue reliabilist approach to epistemic normativity we defend in Knowledge, Dexterity and Attention (Fairweather and Montemayor 2017). Like Ganeri, we argue that the psychology of attention is the best psychology for epistemology. However, contra Ganeri, we argue that a normatively adequate attentionalist epistemic psychology requires a minimal notion of a causally efficacious agent. We understand the success of the minimal agent in terms of cognitive dispositions that reliably manifest attention's insensitivity to defeaters and distractors and the internal normative force of attentional anchoring through cognitive constitution and control (Fairweather and Montemayor 2017, chapters 4-6.)

A middle point between the modularity defended by Ganeri and a robust notion of self will appeal to a minimal agent that sustains forms of virtuous sensitivity and insensitivity that operate at different stages of cognitive processing (e.g., conceptual, inferential, expertise-based). We propose that Ganeri's account of knowledge and justification, based on attentional capacities, is best understood in terms of virtue reliabilism and the presumption of a minimal epistemic agent. This allows for enough automaticity to exploit the virtues of modularity, and enough agency to account for epistemic responsibility and other normative evaluations of belief. In this way, the attentional turn Ganeri defends can be very productive for clarifying the epistemic psychology that supports normative epistemology.

Finally, we would like to briefly assess similar issues with respect to moral responsibility. It seems that moral responsibility may require a more robust sense of self, because moral evaluation seems to depend more fundamentally on explicit judgment. Here the problem is that if Ganeri chooses to construe the morally relevant normativity of attention in responsibilist terms, the threat of situationism is more significant than in epistemology (Fairweather and Montemayor 2017, chapters 1 and 2). This interpretation would also jeopardize the no-self commitments of his view. Here an option is to adopt a view similar to Iris Murdoch's (1970), according to which we must immediately attend to the needs of others, without representing them in terms of personal evaluations, in order to be morally praiseworthy. Such an approach is indeed very much in line with various views Ganeri endorses about 
empathetic attention, but its empirical verification is more contested than in epistemology. This possible asymmetry in the psychological analysis of epistemic and moral responsibility is another area for further exploration concerning Ganeri's important book.

\section{QUESTIONS}

At the end of this writing, we raise the following engaging questions: (1) How does Ganeri's approach address the traditional objections to functionalism about phenomenal consciousness? (2) What is the contribution of consciousness to epistemic or moral responsibility? (3) How does the attentional turn he calls for would impact work in contemporary epistemology? (4) What is the role of agency and motivation in his theory of attention? (5) Given Ganeri's emphasis on dispositions and attention capacities, is a virtue theory the best way for him to account for epistemic value? (6) Can Ganeri's attentional approach provide an alternative explanation of the source of epistemic value? (7) Does Ganeri's attentional approach actually suffice to define a minimal epistemic agent or self, in which case it is a welcome addition to the epistemic psychology of virtue epistemology and the normative turn more generally?

\section{REFERENCES}

Arnold, D. (2008), Review of "The Concealed Art of the Soul: Theories of Self and Practices of Truth in Indian Ethics and Epistemology", by Jonardon Ganeri, Notre Dame Philosophical Reviews April 28.

Block, N. (1995), "On a confusion about a function of consciousness, Brain and Behavioral Sciences 18.2: 227-247.

Brooks, T. (2013), Review of "The Lost Age of Reason: Philosophy in Early Modern India 1450-1700", by Jonardon Ganeri. Notre Dame Philosophical Reviews, March 3.

Chalmers, D. (1996), The Conscious Mind: In Search of a Fundamental Theory (Oxford, UK: Oxford University Press).

Fairweather, A. and Montemayor, C. (2017). Knowledge, Dexterity, and Attention: A Theory of Epistemic Agency (New York, NY: Cambridge University Press).

Ganeri, J. (2017), Attention, Not Self (New York, NY: Oxford University Press).

Greco, J. (2010), Achieving Knowledge: A Virtue Theoretic Account (New York, NY: Cambridge University Press).

Montemayor, C. and Haladjian, H. H. (2015), Consciousness, Attention, and Conscious Attention (Cambridge, MA: MIT Press).

Murdoch, I. (1970), The Sovereignty of Good (New York, NY: Schocken Books).

Nagel, T. (1974), "What is it like to be a bat?", Philosophical Review 83: 435-450.

Pritchard, D. (2012), "Anti-luck virtue epistemology", Journal of Philosophy 109: 247-279.

Sosa, E. (2015), Judgment \& Agency (Oxford, UK: Oxford University Press).

Westerhoff, I. (2013), Review of "The Self: Naturalism, Consciousness, and the First Person Stance", by Jonardon Ganeri. Notre Dame Philosophical Reviews January 29.

Zagzebski, L. (1996), Virtues of the Mind (Cambridge, UK: Cambridge University Press). 